\title{
ENTRE ARQUITETOS E LITERATOS: IMAGENS DE LIMA COMO CIDADE LATINO- AMERICANA (1950-1970)
}

\author{
Ana Claudia Veiga de Castro' 1 , https://orcid.org/0000-0001-9922-9806, $\underline{\text { anacvcastro@ usp.br }}$
}

1 Universidade de São Paulo, 05508-050, São Paulo - SP, Brasil

Submitted: 31/07/2020. Accepted: 03/08/2021. Published: 29/09/2021

\begin{abstract}
RESUMO
Objetivo: Esse artigo pretende tomar a cidade de Lima entre as décadas de 1940 e 1970 para um exercício de análise que relaciona as múltiplas dimensões que definem as cidades, com ênfase na dimensão das representações, em busca de contribuir para a história cultural urbana na América Latina. Metodologia: Cruzamento entre os discursos especializados de arquitetos, urbanistas e sociólogos com os discursos não especializados das narrativas literárias, dentro dos marcos da história cultural urbana. Resultados: O período enfocado é justamente o momento em que a cidade que se moderniza, vivendo os efeitos do segundo pós-Guerra. Como outras cidades do sub-continente, Lima vive a intensificação do processo de urbanização com consequências que marcam até hoje sua paisagem. O surgimento das barriadas, ocupações precárias ao redor do casco histórico, contrasta com o investimento na edificação de unidades vecinales, grandes conjuntos habitacionais que sintetizam os esforços da modernização urbana e arquitetônica do país. Contribuição para o conhecimento: Ao lermos as narrativas dos literatos juntamente aos textos dos arquitetos veiculados na revista El arquitecto peruano - EAP, percebemos como esses últimos demoram a perceber como a modernização da cidade dependia desses sujeitos que brotavam nas bordas da cidade.
\end{abstract}

PALAVRAS-CHAVE: Lima, cidade latino-americana, arquitetura e urbanismo, literatura, história cultural urbana

\section{BETWEEN ARCHITECTS AND LITERATES: IMAGES OF LIMA AS A LATIN AMERICAN CITY (1950-1970)}

\begin{abstract}
Purpose: This article intends to take the city of Lima between the 1940s and 1970s for an analysis exercise that relates the multiple dimensions that define cities, with an emphasis on the dimension of representations, seeking to contribute to urban cultural history in America Latin. Methodology: Crossing the specialized discourses of architects, urban planners and sociologists with the non-specialized discourses of literary narratives, within the framework of urban cultural history. Results: The period focused on is precisely the moment when the city is being modernized, experiencing the effects of the second post-war period. Like other cities on the sub-continent, Lima is experiencing the intensification of the urbanization process with consequences that still mark its landscape. The emergence of barriadas, precarious occupations around the historic town, contrasts with the investment in the construction of vecinales, large housing complexes that synthesize the efforts of urban and architectural modernization. Contribution to knowledge: When we read the narratives of the literati along with the texts of the architects published in the magazine El arquitecto peruano - EAP, we observe a long time to realize how the city modernization dependeds on these subjects that sprang up on the edges of the city.
\end{abstract}

KEYWORD: Lime, latin american city, architecture and urbanism, literature, urban cultural history 


\title{
1. INTRODUÇÃO E METODOLOGIA
}

\author{
La "barriada" - dont la traduction française sous le terme de "bidonvilles" paraît inadéquate - \\ est une des versions du mode d'urbanisation accéléré qui semble être caractéristique en Amérique \\ latine. Ce phénomène a fait l'objet de nombreuses études et interprétations de la part d'architectes (J. \\ Turner), de psychiatres (H. Rotondo), de sociologues (W. Mangin, J. Matos Mar) et même de \\ l'administration péruvienne. Une loi votée en 1965, régularisant ce mode d'urbanisation, a été préparée \\ par la Junta de Vivienda (Corporation de l'habitat), aujourd'hui remplacés par de Ministère des \\ "Pueblos Jóvenes", nouvelle dénomination pudique désignant les "barriadas" et qui est à l'origine d'un \\ décret-loi paru en 1969. Mais ces études manquent de sûreté, ou bien sont trop partielles. Ainsi, \\ l'évaluation de la population des barriadas varie-t-elle entre $10 \%$ et $25 \%$ de la population totale de \\ Lima. Ces "barriadas" totalisaient en 1961 environ 100000 habitations." \\ Jacqueline Weisslitz, Migration rural et integración urbaine au Perou, 1972
}

As conexões entre literatura, história e cidade há tempos têm sido objeto de interesse de estudiosos que periodicamente revisitam o tema e buscam em seus escritos estabelecer e discutir os rendimentos dessa ligação (Bradbury \& Mcfairlaine, 1998; Anhein \& Lilti, 2010; Bresciani, 2018; Leite, 2021; Iegelski, 2021; Coutinho, 2021; Castro, Lira e Silva, 2021). Ao tomar a cidade, artefato construído, para além da sua dimensão material, reivindicando também sua condição de arena de conflitos e tensões, bem como de imagem e representação - compreendendo-as como "três dimensões solidariamente imbricadas, cada uma dependendo profundamente das demais em relação simbiótica" (Meneses, 1996, p. 149) -, esse artigo pretende tomar a cidade de Lima entre as décadas de 1940 e 1970 para um exercício de análise, enfatizando a leitura dessas representações em busca de contribuir para a história cultural urbana das cidades na América Latina.

A capital do Peru encarna uma imagem importante da "cidade latino-americana": seu passado colonial como la Ciudad de los Reyes deixa marcas, constituindo o artefato urbano, e esse artefato é vivido ao longo de sua história entre embates e tensões que geram representações conflitantes. São essas representações de Lima como cidade latino-americana - em especial as que surgem da pena dos literatos e dos arquitetos e urbanistas - que nos interessam aqui recuperar.

A cidade se moderniza, após a Segunda Guerra, quando a população urbana cresce enormemente, passando de 203 mil habitantes em 1920 a 520 mil em 1940, chegando a 1.370 .000 em 1957 (Huapaya, 2014). Nesses anos começam a surgir ocupações precárias ao redor do casco histórico, as barriadas, que contrastam com o investimento estatal na edificação de unidades vecinales, grandes conjuntos habitacionais que sintetizam os esforços da modernização urbana $\mathrm{e}$ arquitetônica do país (Kahatt, 2015).

Segundo os estudos pioneiros do sociólogo José Matos-Mar (1977), o primeiro agrupamento que poderia ser chamado de barriada surge na cidade de Lima por volta de 1946, em San Cosme, espalhando-se a partir daí pela colina de San Cristóbal, nas margens do rio Rímac, chegando ao Deserto de San Juan já na década de 1950. Em Las barriadas de Lima, 1957 Matos Mar apresenta informações do censo de 1956, identificando a maioria daqueles habitantes como "serranos". Ou seja, era a população do altiplano andino que "descia" para a capital em busca de melhores condições de vida, que não tendo onde morar construía suas casas precárias nas bordas da cidade.

Essa migração campo-cidade, como se sabe, não foi algo particular do Peru, e sobretudo após 1945 foi vivenciada de modo intenso nos vários países latino-americanos, provocando efeitos mais ou menos similares nas suas cidades. Mas foi apenas na década de 1960 que as favelas passaram a ser compreendidas como algo incontornável na paisagem urbana, momento que o próprio termo "periferia" é incorporado no vocabulário dos estudos urbanos, confundindo-se muitas vezes com o sentido da "favela" (Codognoto, 2021).

O crescimento populacional impulsiona o governo a estabelecer um Plan Nacional de Viviendas em 1945, já que desde pelo menos 1936 o Estado promovia algumas experiências de habitação social. Nesse ano fora criado o Servicio de Inspecciones de la Vivienda Obrera, como parte da Dirección de Previsión Social do Ministerio de Salud Pública, Trabajo y Previsión Social, e através do Ministerio de Fomento y Obras Públicas se iniciaram as construções dos bairros 
operários de La Victoria e Rimac, localizados em áreas periféricas da cidade velha (Huapaya, 2014).

Ambas as experiências - os conjuntos habitacionais modernos e as barriadas - marcam o discurso dos arquitetos e urbanistas que defendem a edificação de uma Lima moderna nas páginas da revista El arquitecto peruano, gerando imagens conflitantes. A revista, nesse sentido, é uma importante arena de debates sobre o presente, o passado e o futuro da cidade, onde são publicados não apenas os novos projetos urbanos que redefinem partes do tecido urbano, mas também as ideias e os fundamentos dessa renovação, sintetizadas em imagens de uma cidade industriosa, ciente da força de seu passado e pronta a enfrentar os desafios de seu futuro (Santos, 2017). Segundo Adrián Gorelik (2005), as cidades na América Latina teriam durante aqueles anos funcionado como uma espécie de "bomba de sução", atraindo figuras, disciplinas e instituições que desenham um novo mapa intelectual, acadêmico e político no continente, no qual o mundo urbano - em suas potencialidades e em seus problemas - tem uma inquestionável centralidade. Se essas cidades compartilham uma história comum (Díaz-Márquez, 2019), é importante pensar também que há uma série de especificidades.

\section{METODOLOGIA}

É nesse contexto de aproximações e afastamentos, de similaridades entre elas, mas também de muitas particularidades, que se nota como a chamada Generación del 50, que reunia escritores peruanos como Julio Ramón Rybeiro, Enrique Congrains, Carlos Zavaleta, Vargas Vicuña, Sebastián Salazar Bondy, Mario Vargas Llosa, entre outros, também produzia imagens da cidade nas suas narrativas literárias (Rama, 2001). Nesses textos, Lima não é vista apenas cenário ou pano de fundo para as tramas, mas surge como um personagem, que provocava reações, paixões, medos e desejos. O título Lima la horrible (Salazar Bondy, 1963) parece sintetizar esse protagonismo. É desse contexto que se identificam as fontes para o presente artigo, e que colaboram para sua base metodológica; trata-se de uma discussão exploratória voltada a um conjunto de obras e autores que apresentam de uma cidade em transformação, Lima.

Pode-se pensar, assim, que tanto a literatura, o discurso ficcional dos literatos, como o discurso especializado dos arquitetos (mas também o dos sociólogos e antropólogos), aportam elementos para a construção das imagens da cidade, contribuindo para fazer de Lima um artefato complexo e contraditório, uma figura multifacetária. São esses discursos - nos quais se busca ler as representações da cidade que surgem no período - que esse artigo busca destacar.

\section{O DISCURSO ESPECIALIZADO - A LIMA DOS ARQUITETOS MODERNOS}

Talvez o mais importante meio de circulação das ideias dos arquitetos e urbanistas sobre a cidade de Lima tenha sido a revista El Arquitecto Peruano (EAP). Criada por Fernando Belaúnde Terry, a revista circulou entre 1937 e 1977, sendo dirigida por ele até 1963, quando passou às mãos de seu sobrinho, Miguel Cruchaga. Formado nos Estados Unidos (na Universidade do Texas), Belaúnde iria protagonizar uma série de ações no sentido de consolidar o campo da arquitetura e urbanismo desde sua volta em 1936, criando instituições chave, como a Sociedad de Arquitectos del Peru, o Instituto de Urbanismo del Peru (IUP), em 1944, a Oficina Nacional de Planeamiento y Urbanismo (ONPU) e a Corporación Internacional de Vivienda, ambas em 1946. Em 1945, Belaúnde se tornou deputado federal e passou a discutir e aprovar leis para organizar as cidades peruanas e possibilitar a construção de conjuntos habitacionais. Em 1963, já como presidente da República, teve a chance de implementar suas ideias, ainda que o contexto distinto da década de 1960 o tenha levado a alterar parte de seu discurso (Zapata, 1995; Huapaya, 2014).

A EAP, figura 1, teve 356 edições com uma média de 50 páginas e com uma periodicidade variada entre as décadas: inicialmente, edições mensais; a partir de 1951, bimestrais; e após 1958, na maioria dos anos seriam lançadas 4 edições (Santos, 2017). Além de Belaúnde, outros nomes 
escreveram ali regularmente, como Eduardo Neira, Rafael Marquina, Héctor Velarde, Luiz Ortis de Zevallos, Alfredo Dammert, Carlos Morales Machiavello e Luis Dorich, profissionais que ao compartilhar ideias e concepções de mundo, buscavam afirmar o progresso e o bem-estar social prometido pelo ideário moderno (Zapata, 1995; Huapaya, 2014; Kahatt, 2015; Caldas Torres, 2016; Kahatt, 2020; Dioses, 2020). Pelas páginas da revista tomamos contato com uma Lima moderna e industriosa, construída a partir da modernização da infraestrutura urbana. Entretanto, ao longo das décadas é possível notar alguns movimentos que indicam uma paulatina mudança no discurso dos arquitetos, alterando a imagem da cidade.

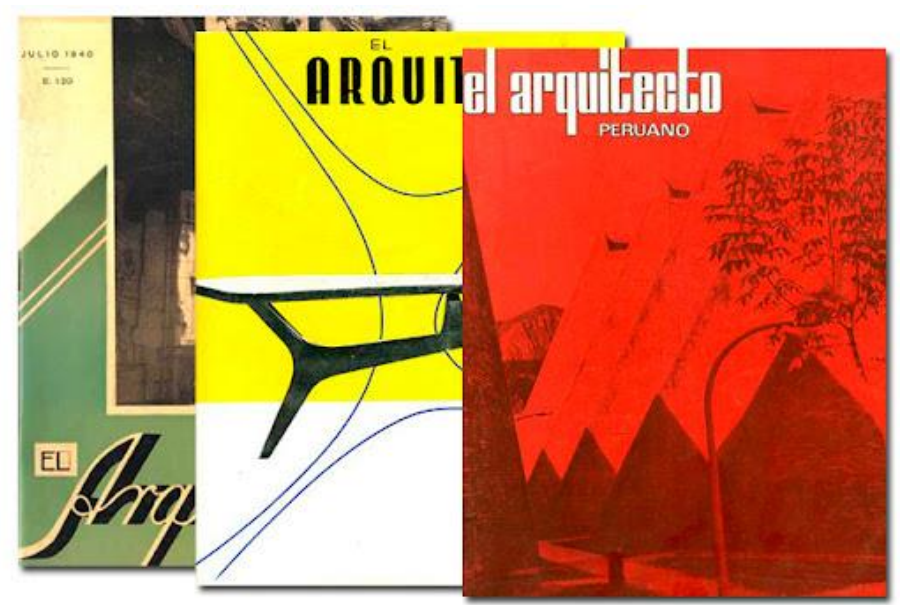

Figura 1. Capas da Revista El Arquitecto Peruano (1930-1970) (Fonte: Reprodução/ http://www.elarquitectoperuano.com)

Antes de 1940 e durante os anos da Segunda Guerra, defende-se que a cidade não deveria se render às transformações que se impunham com a modernização, pois isso apagaria a cidade de origem hispânica. $\mathrm{O}$ arquiteto Harth Terré afirma:

No se debe permitir traducir en nuestras ciudades de plano colonial, lo que otras ciudades del mundo han realizado ante un estado de cosas que no tenía más remedio elevando sus casas hasta las nubes y haciendo de ellas torres de audácia. (Cf. Harth-Terré, Decálogo urbano, EAP, n. 8, mar., 1938, p.33-34).

Com o fim da Guerra e a incontestável mudança do centro de poder do mundo para os Estados Unidos, algumas mudanças se impõem e Belaúde, figura 2, que havia tido a oportunidade de conhecer pessoalmente os programas do New Deal voltados à produção habitacional, torna-se um dos porta-vozes da aproximação à América do Norte. A partir daí a atenção à questão habitacional passa a ser constante, sendo a vivienda obrera a garantia do surgimento do novo homem, substrato da família, e pilar da manutenção da ordem (Cf. La vivienda obrera em el Perú, $E A P$, n. 26, set., 1939, p. 20-24, entre outros). A falta de habitação é diretamente relacionada aos problemas de mortalidade, o que colocava em risco o próprio desenvolvimento do país. Entre as décadas de 1940 e 1950 os textos que retomam esse problema reconhecem os riscos de não se enfrentá-lo de modo efetivo. Lima, dessa forma, se via em uma encruzilhada de caminhos.

El habitante promedio de Lima vive en la actualidad 39 años. Esta expectación de vida que tiene una criatura al nacer es una de las más bajas del mundo e implica no solo una mortalidad elevada, sino también refleja la pobrísima salud de la población. / Es innegable que la vivienda es un elemento de importancia decisiva en la conservación del capital humano. También es innegable que la mayor parte de la población de Lima vive en habilitaciones insalubres, lóbregas y estrechas en que se destruyen el vigor y la vitalidad de la raza. La magnitud del problema se acrecienta a medida que disminuye el nivel económico de la población. Para las 
clases obreras el problema es angustioso. Veamos qué se ha hecho para resolverlo (Cf. El eterno problema de la vivienda, EAP, nov., 1946, p. 25).

Ser uma cidade moderna então significava prover "habitação moderna" para seus habitantes, transformando consequentemente as formas de vida. Ou seja, urbanizando seus habitantes na dupla acepção da palavra, de construir cidade e torná-los cidadãos por meio dela.

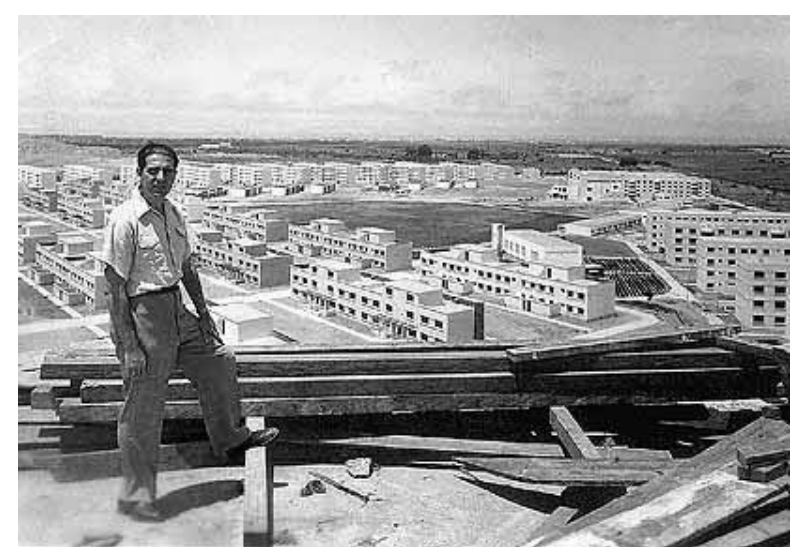

Figura 2. Fernando Belaunde Terry e a Unidade Vecinal n. 3 (c. 1945). Fonte: Huapaya (2014, p. 321)

O enfrentamento vinha se dando efetivamente pela construção de novos bairros, as unidades vecinales, que eram previstas para funcionar como polos de desenvolvimento, na medida em que muitos deles, construídos fora do perímetro urbanizado, constituíam novas frentes de expansão da cidade.

Se impone, pues, la descentralización por medio de Unidades Vecinales, como la No. 3, cuya consagración ha venido a despejar dudas y a destruir mitos. Contrariamente a lo temido se ha podido probar, en la practica, que el pueblo de Lima tiene la aspiración y la capacidad para vivir mejor y que puede cumplir con el pago de alquileres razonables que no sean fruto de la caridad o la demagogia (Cf. Foro urbanístico sobre la ciudad de Lima, EAP, nov., 1950, p.819).

Quando em 1945, com a criação da Corporación Nacional de Vivienda, é construída a Unidade Vecinal n. 3, materializa-se finalmente a ideia de que é possível transformar a realidade. Por meio de um saber técnico especializado e da vontade política, "a cidade" tomava as rédeas de seu futuro, evidenciando a modernização que se esperava.

Solamente en 1945 la creación de la Corporación Nacional de la Vivienda, estableció una actitud seria e idónea frente al problema. Por primera vez en nuestra historia la crisis de la habitación se enfocó técnicamente y con medios apropiados. El primer resultado, la Unidad Vecinal No 3, sigue siendo la expresión, de un momento en el cual se creyó encontrar una respuesta a la desesperada situación de millones de peruanos (Cf. Neira, Eduardo, El problema de la vivienda, EAP, nov., 1946, p.40-47).

Mas o reconhecimento do papel do Estado como provedor e condutor dos caminhos não eximia o papel que cada cidadão devia assumir diante dos problemas a serem enfrentados:

Si todos cooperásemos; si los ingenieros, los gobernantes, los inversionistas, los obreros, los empleados actuáramos en conjunto y cada cual dentro de su posibilidades, el problema estaría resuelto. Hay múltiples formas de conseguirlo. Contamos con los medios, los hombres, y los planes. El momento es ahora. (Cf. El eterno problema de la vivenda, EAP, n. 64, nov., 1942, p.25) 
Nota-se no discurso dos arquitetos que "Lima tem força" porque é uma cidade feita de "homens fortes" - e, contra as piores expectativas, podia vencer os desafios. Se havia barriadas, se havia tugúrios, se havia callejones, em uma palavra: se havia pobreza urbana, Lima já estava pronta para superá-la. Bastava, além de implementar o novo programa, deter as urbanizações espontâneas e clandestinas que surgiam ao redor da cidade.

Ocorre que em meados da década de 1950 essas urbanizações iam aumentando de maneira espantosa e "los barrios de Leticia, San Cosme, Santoyo, Piñonate, Azcona, etc., já representa[bá]n una verdadera plaga, una muestra elocuente de incultura y de miseria" (Cf. La incultura de las ciudades, EAP, n. 183-184, out.-nov., 1952, p. 3), o que colocava em risco a própria modernização. Que Lima, afinal, seria construída nesses anos, se não se detivesse aquela "praga"?

¿Qué pueden significar las buenas urbanizaciones, los hospitales, los parques, si un cinturón de tugurios rodea y amenaza a toda la ciudad? ¿Existe manera de contener una epidemia en sectores que están caracterizados por el hacinamiento, la insalubridad y la carencia de los más elementales servicios públicos? ¿Los gérmenes, propagados en gran escala en tales sectores, exigen acaso un carnet de identidad a quienes viven decentemente para excluirlos como victimas? (Cf. La incultura de las ciudades, EAP, n. 183-184, out.-nov., 1952, p. 3).

Os arquitetos, se reconheciam os riscos, estavam convencidos da única solução possível: projetar unidades vecinales e transformar de maneira indiscutível não apenas a vida urbana, mas a imagem da cidade. O novo programa seria capaz de extirpar os males, desde que também se detivesse a vinda dos serranos para a cidade. Ou seja, as barriadas eram vistas uma ameaça real, sendo imprescindível deter seu avanço. Junto a um programa habitacional na capital, era "una política de descentralización que el país urgentemente reclama[ba]" (Cf. La hoja de urbanismo, $E A P$, n. 205-206, set.-out., 1954, p.43). O sucesso do programa habitacional dependia de um planejamento regional que integrasse as demais regiões, oferecendo oportunidades de fixação daquela população em seus lugares de origem (Cf. Planeamiento regional para el Perú, EAP, n. 183-184, out.-nov., 1952, p.34-35).

Mas durante os anos de 1950, sobretudo na segunda metade, é possível notar como, paulatinamente, a imagem da Lima moderna que venceria os males das barriadas, figura 3, foi cedendo lugar a outra, que se impunha pela percepção de um processo incontornável: as barriadas não eram urbanizações provisórias. Vinham para ficar. A transformação que então vai se operar no discurso é sutil, mas perceptível.

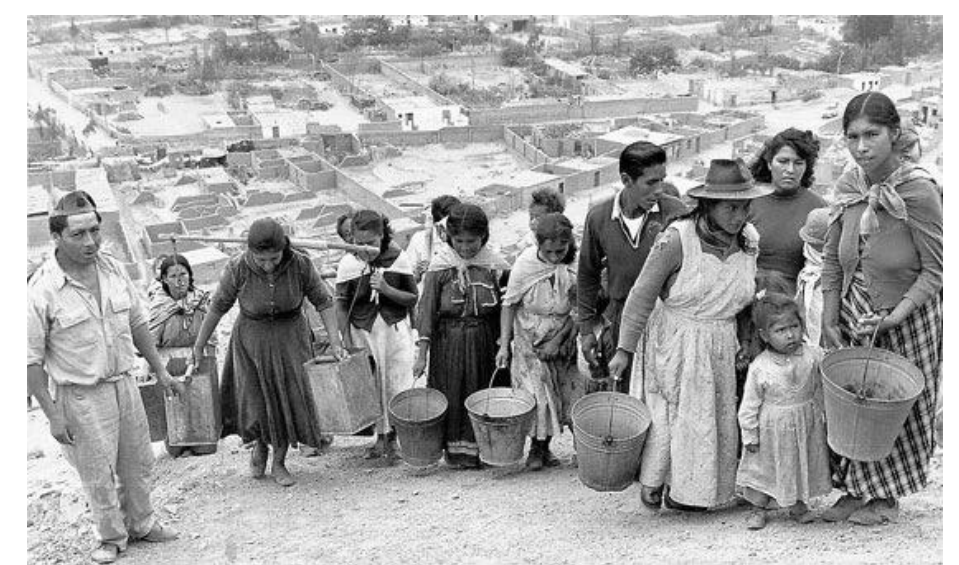

Figura 3. Barriada El Agustino ao redor de Lima (c. 1950). (Fonte: https://elcomercio.pe/blog/huellasdigitales/2015/01/los-50-anos-de-el-agustino)

Em alguns textos publicados na revista naquela década - pontos de vista, editoriais, matérias assinadas - começa-se a propor, juntamente à defesa do programa das unidades vecinales, que o déficit habitacional passasse a ser enfrentado com a construção de unidades menores, ou mesmo 
que se recorresse a uma ação que vinha sendo debatida fora do Peru, incentivada por técnicos norteamericanos: a aposta na ajuda-mútua.

Assim, antes mesmo que John Turner visite o país em 1963 - o arquiteto inglês que ao tomar contato com as barriadas limeñas passou a defendê-las como solução ao problema habitacional da América Latina (Ballent, 2014) -, o peruano Eduardo Neira demonstra vontade de pensar uma Lima moderna que não jogasse fora sua tradição, mas que buscasse nela um equilíbrio perdido desde a Conquista, apontando para isso o caminho da ajuda mútua:

La ayuda mutua, sistema largamente debatido pero jamás ensayado entre nosotros debe tener un gran porvenir. Coronado por un gran éxito en todos los lugares donde ha sido empleado tiene en el Perú el apoyo de una tradición milenaria sus posibilidades son ciertamente inmensas y podría ser utilizado por las mencionadas sociedades cooperativas. La ayuda mutua será singularmente favorable en aquellos lugares del país donde las condiciones de vida son desarrolladas y donde la sencillez de las viviendas hace posible el empleo de mano de obra no especializada (Cf. Neira, Eduardo, El problema de la vivienda en el Peru, EAP, n. 224-225, mar.abr., 1956, p.40-47).

Ora, mas aqui não era a origem hispânica que interessava, como acontecia nos anos 1930, e sim a tradição pré-colombiana, rompida justamente pela chegada do conquistador. Esse tipo de percepção parece ser a senha que vai levar a uma explícita transformação de discurso. O próprio Belaúnde recorre ao "hábito ancestral de la cooperación popular, la vieja minka que hizo grande al Imperio y cuyas características perduran en las comunidades" para justificar a mudança que se opera em seu discurso de arquiteto moderno:

Si las naciones pudieran acudir a los médicos en busca del diagnóstico de sus males el Perú confirmaría su grave dolencia crónica que, afortunadamente, no es incurable: la decadencia agónica de sus villorios. Porque, como todo enfermo, el país tiene en si mismo la defensa orgánica para combatir el mal que le aqueja: el hábito ancestral de la cooperación popular, la vieja minka que hizo grande al Imperio y cuyas características perduran en las comunidades. (Cf. Belaunde Terry, Fernando. Cooperación popular, EAP, n. 237-238-239, abr.-may.-jun., 1957, p.31-33).
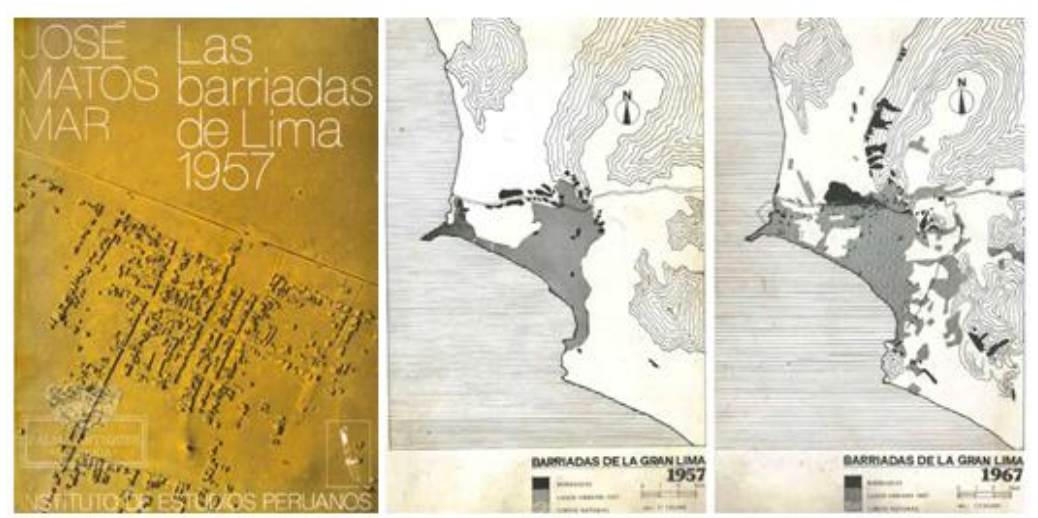

Figura 4. José Matos Mar, Las barriadas de Lima, 1957. (Fonte: Reprodução)

Dessa forma, nota-se que em fins dos anos 1950, após a publicação de Matos Mar sobre as barriadas, figura 4, começam a surgir textos que buscam valorizar a autoconstrução, ainda que não em Lima, mas em outros pontos do país, menos urbanizados, e que por isso mesmo poderiam apoiar-se nessa tradição com mais tranquilidade:

El 29 de Junio de 1958 tuvo lugar, en una ceremonia plena de sencillez, la colocación de la primera piedra de la Escuela Fiscal No. 4343 del pueblo de Lurigancho. No merecería esta actuación, una cita periodística tan extensa, si, como 
tantas otras de la misma índole, se concretara tan sólo a poner en marcha la edificación de una escuela más, hecho que si bien tiene de por sí un gran valimiento, no alcanza en modo alguno a igualar al que enviste esta humilde ceremonia, porque la Escuela No. 4343 de Lurigancho ha sido construida con el trabajo de los padres de familia del lugar y el aporte económico de los agricultores del valle, en una evidente demostración de lo que puede realizar la cooperación humana cuando sus factores socio- económicos marchan en armonía. (Cf. El Pueblo lo hizo..., EAP, n. 258-259260, jan.-fev.-,mar., 1959, p.12-13).

Ou ainda:

En el Perú están enclavadas, en lo remoto de la historia, las más hondas raíces de la comunidad agraria y del trabajo mancomunado o minka la muy en boga "ayuda mutua" de la hora actual. ¿Estará en su destino dar al continente una solución de comunidad urbana contemporánea, a tono con las nuevas necesidades y haciendo uso de la técnica moderna? Ello depende de nosotros mismos... (Cf. Puntos de Vista: Cooperativas de habitación obrero-patronales, EAP, n. 210-211, jan.-fev., 1955, p. 3).

Tratava-se de reatar a tradição construtiva rompida pela Conquista, reconhecendo saberes dos povos originários - ou seja, não os vendo como incivilizados que precisavam ser incorporados à ordem moderna - desde que permanecessem em seus locais de origem.

Nesses anos, enquanto o tema da vivenda social segue sendo fundamental para os arquitetos, as ações estatais e disciplinares se intensificam, com a criação de instituições públicas de planejamento, edificação e ações legislativas muito objetivas. Ao mesmo tempo, o reconhecimento de uma paisagem cultural e social comum em toda a América Latina também se intensifica, indicando a necessidade de uma organização regional. Mas isso não impedia que os Estados Unidos se mantivessem como um parceiro importante, que agora "ensinava", com sua expertise nos campos econômico e planificador, o subcontinente, e mais especificamente, o Peru, também sobre a autoconstrução. Se alternativas de construção e ajuda-mútua surgem na pauta - de par com as discussões sobre planejamento e financiamento da habitação -, para os arquitetos, seus programas habitacionais modernos seguem valendo como um norte a ser perseguido.

Talvez se possa dizer que há uma espécie de entrelaçamento entre as representações da cidade e a representação do próprio arquiteto como profissional. Pois é na construção do seu lugar social - e do campo disciplinar do arquiteto - que Lima passa a oscilar entre a cidade moderna e uma modernização temperada pela tradição. Tradição que, por sua vez, oscilaria entre a cidade dos incas e a cidade dos reis católicos. A inauguração de Brasília, evento que comprova o papel dos arquitetos e urbanistas na inserção do subcontinente na modernidade, que abre a década de 1960, na revista é então tomada como oportunidade para reconhecer em Lima a mesma função: a cidade fundada para dominar o território, fadada desde então a ser grande na América. Traça-se a assim linha que une três tradições:

La fundación de Lima por los españoles es el caso típico del establecimiento de una ciudad planeada con fines político-administrativos y, aunque el valle estaba ya densamente poblado, pudo colocarse en la ribera del Rímac, en terreno libre, una ciudad geométrica, trazada a cordel. Llegaba al Perú la influencia del predominio naval que, según se ha anotado en el caso de Brasilia, tiende a ceder su lugar al predominio aéreo, facilitando una saludable tendencia centrípeta, que ha de estimular la incorporación de vastas regiones a la economía incipiente de nuestros países. (Puntos de Vista: Cuzco-Lima-Brasília, n. 270-271-272, EAP, jan.-fev.mar., 1960, p. 3).

Quando em 1963 Belaúnde se elege presidente, a revista perde seu principal nome, e os números se tornam menos constantes. Ao mesmo tempo, o reconhecimento da incapacidade de se deter as urbanizações clandestinas e precárias, em crescimento constante, passam cada vez mais a 
levar os arquitetos às soluções menos ortodoxas, e o próprio presidente-arquiteto assume essa possibilidade.

O famoso concurso PREVI-Lima de 1969 consagra esse novo momento. Ali, arquitetos modernos do mainstream internacional se uniam a arquitetos peruanos para promover um plano piloto, sob a inspiração de Turner e a direção do arquiteto norte-americano Peter Land, com unidades que poderiam ser completadas pelos usuários - misturando-se à paisagem. Treze equipes internacionais foram selecionadas: Candilis Josic e Woods (França), Aldo van Eyck (Holanda), Oskar Hansen e Svein Hatløy (Polónia), James Stirling (Reino Unido), metabolismo Kikutake, Maki e Kurokawa (Japão), Atelier 5 (Suíça), Knud Svenssons (Dinamarca), Toivo Korhonen (Finlândia), Iñiguez de Onzoño e Vasquez de Castro (Espanha) Herbert Ohl (Alemanha), Charles Correa (Índia), Christopher Alexander (EUA) e alemão Samper (Colômbia). A ideia fora apresentada ao Programa das Nações Unidas para o Desenvolvimento em 1966, quando se reconheceu sua condição prototípica para a potencial aplicação dos resultados do projeto no resto do Terceiro Mundo (Ballent, 2011). Turner, num artigo publicado na Architectural Design em 1963, observara e descrevera as etapas de construção das casas dos pobres nas ocupações clandestinas:

(...) primeiro a "choza", uma barraca temporária muito primitiva, à base de tapetes pendurados em canas de bambu; na segunda fase o "cerco" que, como o próprio nome sugere, rodeia a "choza" anterior com paredes de alvenaria; e assim progressivamente os alicerces e o piso, com uma cobertura, quando também se instala a eletricidade, e se iniciam as obras de canalização e de drenagem (Turner, 1963, p.376, tradução nossa).

Ora, as casas projetadas pelos arquitetos podiam seguir raciocínio similar, figura 5, sendo completadas ao longo do tempo e aceitando as transformações dos próprios núcleos familiares não mais funcionando como "civilizadoras". Afastando-se das vanguardas modernistas do início do século, a forma deixava de ser essencial, e a capacidade de adaptação da população local ao território, como estratégia de sobrevivência, passava a inspirar a revisão da própria cultura arquitetônica. É certo que para essa visada contribuíram outros agentes e processos, mas parece ter sido a partir da divulgação dessa discussão pelo arquiteto inglês que formas de habitação consideradas marginais se apresentariam cada vez mais em sua dimensão produtiva, e não apenas formal, como uma saída possível para as promessas de engajamento social da cultura arquitetônica letrada formuladas desde os primórdios do Movimento Moderno. Ballent (2011) mostra como foi crucial para Turner sua proximidade com Eduardo Neira e, também, o próprio processo de conformação da legislação e das instituições de peruanas de planejamento que haviam contado com a importante participação de nomes como José Luis Sert e Paul Lester Winer, ligados ao Movimento Moderno. De fato, vê-se Neira inaugurar a discussão sobre o valor da casa dos pobres na revista $E A P$. E isso também contribuía para mudar a imagem da cidade.

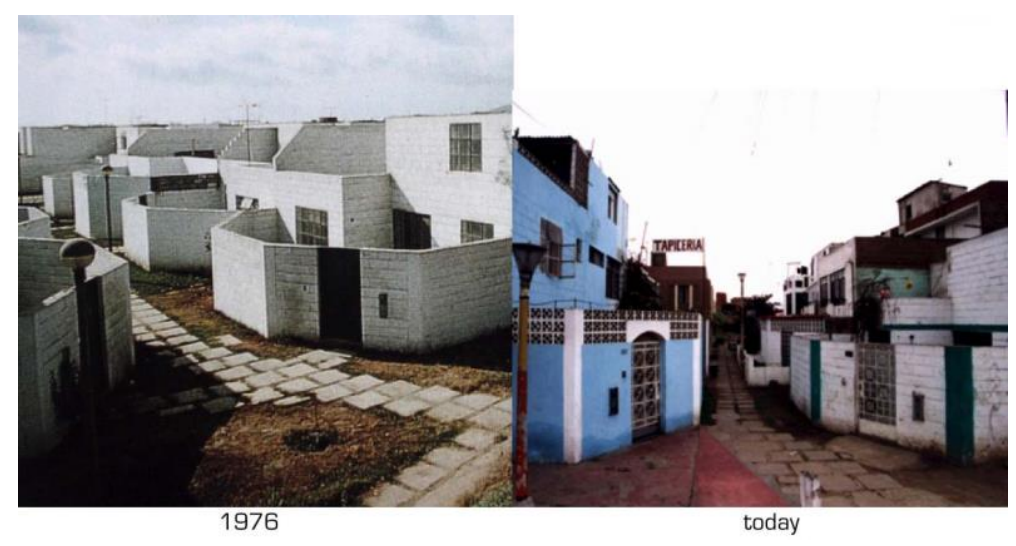

Figura 5. Bairro PREVI-Lima. (Fonte: Supersudaca/ https://51-1.com/Y-PREVI) 
As alternativas para lidar com uma realidade que parecia difícil de se transformar levam Lima a se reconhecer a essa altura como uma cidade latino-americana em busca de enfrentar seus problemas. Nesse caminho, pode-se dizer que a cidade latino-americana se torna cada vez mais uma entidade conhecida e reconhecida pela imagem da precariedade, pelo avanço dos pobres e pela consolidação das periferias urbanas.

\section{O DISCURSO LITERÁRIO - A LIMA DOS ESCRITORES}

Se a Lima dos arquitetos é a cidade moderna e modernizada, que paulatinamente é obrigada a aceitar sua origem (ora hispânica, ora pré-colombiana), e reconhecer as particularidades, bem como as consequências da modernização urbana no lado de baixo do Equador, pode-se dizer que a Lima dos literatos, figura 6, não tem dúvidas quanto ao peso dessas origens e os efeitos dela no presente urbano.

Antes de avançar sobre tais imagens, vale pensar de que modo a literatura pode ser um discurso que ilumina a compreensão urbana. Talvez a pergunta que se deva fazer seja: em que medida a literatura lança novas luzes a processos já conhecidos, permitindo outras e renovadas leituras? Antonio Candido já nos ensinou que a arte é social em dois sentidos, pois que

depende da ação de fatores do meio, que se exprimem na obra em graus diversos de sublimação; e produz sobre os indivíduos um efeito prático, modificando sua conduta e concepção do mundo, ou reforçando neles o sentimento dos valores sociais. Isso decorre da própria natureza da obra e independe do grau de consciência que possam ter os artistas e os receptores da arte (Candido, 1988, p. 21).

Essa compreensão tem interesse na medida em que enfatiza dois polos na literatura, o de sua produção e o de sua recepção, indicando como o mundo social modela a obra mas como também, em certa medida, a obra modela o mundo. Desse modo, a literatura produzida em Lima nesse período é também um elemento importante para a compreensão da cidade, pois que contribui para a consolidação de uma determinada imagem de cidade latino-americana.
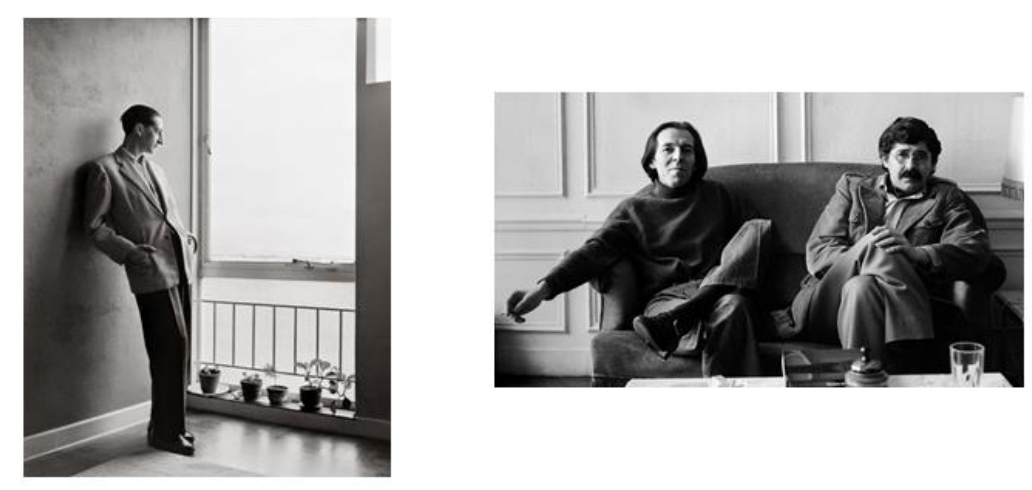

Figura 6. Escritores da Generación del 50: Salazar Bondy (esq.); Julio Ramón Ribeyro e Bryce Echenique (dir.). Fotos de Baldomero Pestana. (Fonte: https://poetasdelfindelmundo.com/imagenes/escritores_peruanos/)

A literatura explorada aqui é a produzida pela mesma geração de arquitetos que debatia suas ideias nas páginas da revista El Arquitecto Peruano. Como parte de uma elite intelectual, tais escritores formavam um grupo que passava a tomar a cidade não apenas como um cenário para suas histórias, mas como matéria para seus livros, novelas, contos e romances, fazendo de Lima quase que um novo personagem. Isso não seria particular de Lima: Angel Rama mostrou que a partir dos anos 1940 há uma importante bifurcação de caminhos, que faz com que as narrativas urbanas 
comecem a ser mais e mais comuns, na medida mesma em que a urbanização avançava no continente. Os literatos iam deixando a poesia e o ensaísmo como formas preferenciais, adotando cada vez mais a prosa como veículo para suas ideias (Rama, 2001, p. 150). Nesse caminho, aparecem livros capitais, como Lima Hora Cero, de Enrique Congrains, em 1954, e Lima La Horrible, de Salazar Bondy, em 1963. Obras que de modo distinto trazem a problemática urbana para o centro da narrativa, explorando a situação vivida pela cidade com a chegada dos serranos e o surgimento das barriadas, e buscando definir, sob a forma ensaio, um ethos peruano.

O livro de Congrains reúne seis contos que trazem para o primeiro plano a Lima marginal da década de 1950. "Rodando, tumbo a tumbo, hemos llegado a Esperanza. Somos más de trescientos entre hombres, mujeres y ninos, y provenimos de todos los rincones del Perú" (Congrains, 1954, p. 11), as duas primeiras frases dão o tom: trata-se de flagrar o processo de formação das barriadas ao redor da cidade, por uma população que se acerca à capital às dezenas, centenas, milhares, e contrasta com a moderna Lima, com os "outros" peruanos, os citadinos:

"Ellos" tinene inmensos edifícios grises; esplendidas casas, rodeadads de esplendidos jardines; tinedas lujosas provistas de todo; garndes hospitales y clínicas; estupensos autos, brillantes y lustrosos; magnifícos colégios para sus hijos" (Congrains, 1954, p. 11).

Não há como não lembrar da frase da Revista El Arquitecto Peruano já citada: “¿Qué pueden significar las buenas urbanizaciones, los hospitales, los parques, si un cinturón de tugurios rodea y amenaza a toda la ciudad?" (La incultura de las ciudades, 1952, p. 3). Esses pobres que rodeiam e ameaçam a cidade são os novos personagens. Segundo Douglas Rubio (2015), entretanto, negando a possibilidade de agência daquela população pobre (vistas no papel de vítimas do sistema), Congrains acabaria por ajudar a fixar um olhar da elite criolla, ao colocar os setores subalternos como quase incapazes de reordenar suas vidas por meio da negociação das regras impostas pelos setores dominantes. Assim, menos que "retrato fidedigno", como o livro foi geralmente lido, a obra contribuiu para que atores sociais importantes na formação da cidade fossem vistos no papel de vítimas, uma imensa massa urbana com pouca potência de transformação. Uma imagem que espelhava a leitura dos arquitetos.

De outra parte, figura 7, Lima la horrible, que não é ficcional, mas um ensaio composto por onze partes, parece poder ser lido na contramão dos contos de Congrains. Para Salazar Bondy, a hegemonia criolla, imposta à custa do silenciamento dos índios e mestiços, causou consequências nefastas ao presente urbano (López Maguiña, 2017; Veja Centeno, 2017). Poder-se-ia aqui propor um diálogo com a leitura de La ciudad letrada, reconhecendo Lima como um epítome da cidade latino-americana desenhada por Rama (Castro, 2017).
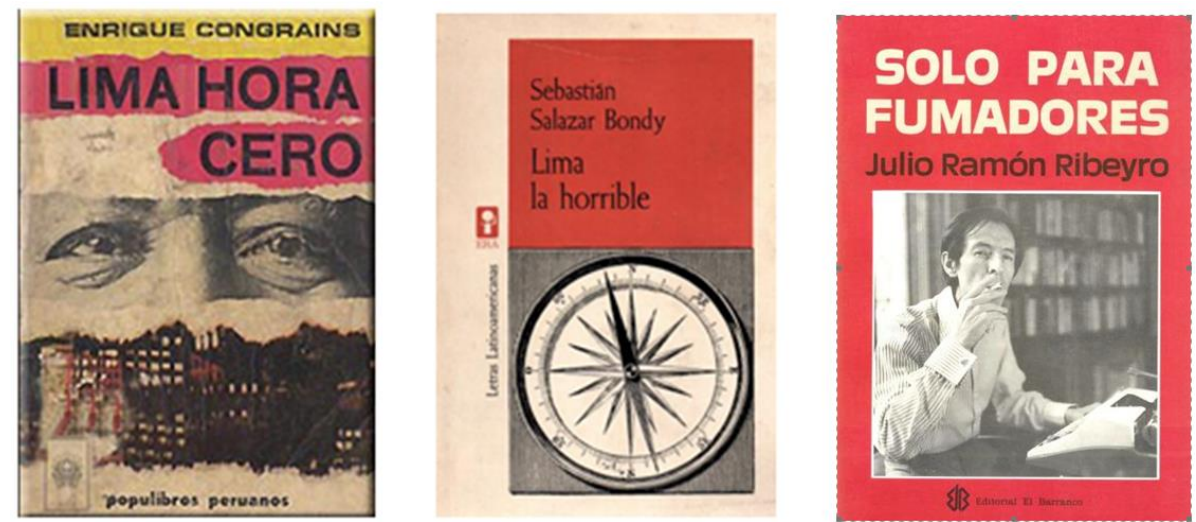

Figura 7. Capas dos livros Lima Hora Cero de Enrique Congrais, 1954; Lima la Horrible de Sebastián Salazar Bondy, 1963 e Solo para fumadores, de Julio Ramón Ribeyro, 1964. (Fonte: Reprodução)

Ao afirmar que "las barriadas populares chorrean paralelas al río desde los cerros eriazos y melancólicos el terral de su miseria, y cercan por otros puntos la urbe con su polvo, su precariedad, 
su tristeza" (Salazar Bondy, 1963, p.97), nota-se, com Felix Terrones (2009), que para o escritor "las barriadas antes que ser parte integrante aunque ancilar de la ciudad no se encuentran integradas a ella". Mas o esforço de Salazar Bondy - que pode ser visto como esforço de sua geração, ainda que com leituras e ações distintas - é o de construir uma identidade para Lima que de algum modo possa abarcar a heterogeneidade racial, econômica e cultural peruana, rompendo com amarras impostas pelo passado. Lima como cidade latino-americana. Nesse caso, positivamente latinoamericana, como quis acreditar outros intelectuais de sua geração, como o arquiteto Eduardo Neira.

Dessa mesma geração, outro autor que interessa ler aqui é Julio Ramon Ribeyro. Informado pela literatura de vanguarda dos países centrais - Joyce, Proust, Faulkner - mas também pelo neorealismo do cinema italiano, as suas narrativas tocam de maneira profunda os problemas de sua época, a cidade de Lima, cidades peruanas imaginadas, a cidade latino-americana. Laura Hossiasson já observou haver nessa literatura:

uma perspectiva sempre deslocada, descentrada, na consideração do mundo social de que trata a narrativa; há uma óbvia inclinação pelo que é aparentemente secundário. (...) Seu alvo são os perdedores, aqueles que não participam do lado eufórico da vida social. (Hossiasson, 2007, p. 285).

É desse modo que o conto "Ao pé da escarpa" pode ser lido: um foco de luz direcionado ao lado não eufórico da modernização. Escrito em 1959 e publicado em 1964 no livro Solo para fumadores, observa a vida limenha na década de 1950 - o autor passaria a viver em Paris como embaixador da Unesco desde 1961 -, por meio da história de uma família pobre, um pai e dois filhos que vivem numa praia deserta perto da cidade. Tentando sobreviver, constroem uma primeira tapera num barranco entre a escarpa e o mar. O conto abre com a imagem de uma figueira-brava, o que nos indica de algum modo de que matéria também é feita aquela gente.

A gente é como a figueira-brava, essa planta selvagem que brota e se multiplica nos lugares mais amargos e escarpados. Vejam como cresce no areal, sobre o seixo rolado, nos córregos sem água, no desmonte, ao redor dos depósitos de lixo. Não pede favores a ninguém, tão somente um pedaço de espaço para viver. Nem o sol, nem o sal dos ventos do mar lhe dão trégua, os homens e os tratores a esmagam, mas a figueira brava continua a crescer, a se propagar, a se alimentar de pedras e lixo. Por isso digo que a gente é como a figueira-brava, nós, a gente do povo. Onde o homem do litoral encontra uma figueira-brava, ele faz sua casa, porque sabe que ali ele também poderá viver. (Ribeyro, 2007, p. 95).

O dia-a-dia difícil, relatado pelo pai narrador, parece fazer parte de um mundo ao mesmo tempo aquém e além da civilização (Hossiasson, 2007). Pouco a pouco, surgem novos personagens naquele mundo vazio: primeiro, um homem de rua se aproxima do pai e presta serviços em troca de comida e abrigo. Depois, alguns veranistas de domingo começam a frequentar a praia e passam a formar uma pequena clientela e a exigir a limpeza e alguma comodidade. Pai, filhos e homem se entregam com afinco à tarefa de limpar a areia e retirar do mar vergalhões de ferro, que impedem o banho. Um filho morre afogado. Subitamente, entretanto, surgem outros pobres, desta vez em maior quantidade e que ocupam o terreno logo acima da escarpa, com seus barracos construídos do dia para a noite. O país conduz a narrativa:

Vão chegar logo! - disse-me Samuel, mostrando umas pedras espalhadas pelo chão - Hoje vi gente rodando por ai. Deixaram essas pedras como sinal. A minha casa é a primeira, mas já já eles vão me imitar.

_ Melhor assim - respondi. Assim não vou ter que ir até a cidade vender peixe. (...)

O Samuel não tinha se enganado. Vieram os que deixaram pedras, e muito mais. Chegavam sozinhos ou em grupos, olhavam a esplanada, desciam pelo desfiladeiro, xeretavam minha casa, respiravam o ar do mar, voltavam a subir, 
sempre olhando para cima e para baixo, apontando, matutando, até que de repente começavam desesperadamente a construir uma casa com aquilo que tivessem ao alcance das mãos. As casas deles eram de papelão, latas amassadas, pedras bambu, saco de aniagem, estacas, tudo aquilo que pudesse fechar um espaço e separá-lo do mundo." (Ribeyro, 2007, p. 105; 110-111).

Homens do governo - ou do mercado, não se sabe ao certo - chegam para inspecionar a área, fazendo medições e mostrando interesse pelos terrenos. O outro filho se casa e vai embora. A polícia busca o homem de rua - era um fugitivo da lei. Querem expulsar os moradores, mas o velho resiste, procurando na cidade um advogado. Diz que está lá há mais de sete anos, o terreno lhe pertence por direito.

Estão jogando a favela no mar.

Eles se contentavam em responder:

É um abuso.

Nós sabíamos, é claro, mas o que fazer? Estávamos divididos, brigados, não tínhamos plano, cada qual queria fazer do seu jeito. Uns queriam ir embora, outros, protestar. Alguns os mais miseráveis, os que não tinham trabalho, se alistaram na companhia e destruíram suas próprias casas.

Mas a maioria foi descendo pela ribanceira. Erguiam suas casas a vinte metros dos tratores para, no dia seguinte, recolher o que sobrava delas e voltar a erguêlas dez metros adiante. (Ribeyro, 2007, p. 123).

Os moradores angariam algum dinheiro para pagar os advogados, mas outros moradores são cooptados. A resistência se desfaz, só o homem permanece. Só que ele também terá que sair, os tratores chegam para derrubar tudo, até sua casa construída com os refugos da expansão urbana. Ele chama de volta o filho, a nora grávida e juntos os três partem para uma nova franja da cidade, um pouco mais distante, onde começam tudo de novo. Ao ver no terreno novo outra figueira-brava, "cavando entre as pedras, fincamos a primeira viga da nossa casa nova" (Ribeyro, 2007, p. 128).

Os personagens estão colocados "frontal e brutalmente entre a mais corriqueira e penosa realidade e a ilusão total" (Echenique apud Ribeyro, 2007, p.10). A ideia de "marginalidade social", ainda que não assim nomeada (Castro e Aravechhia-Botas, 2015), começa a fazer parte dessa realidade que se expressa por meio da literatura, sendo tomada como mote para a criação literária e dela tirando sua força. A ida para uma nova margem não habitada dessa cidade materializa de modo dramático o processo da marginalização. Marginalização de uma população "que brota e se multiplica nos lugares mais amargos e escarpados" dessas cidades. Como afirmou certa vez José Luis Romero:

A história da América Latina é, naturalmente, urbana e rural. Mas, se buscarmos as chaves para a compreensão do desenvolvimento que conduz até o seu presente, será provavelmente nas suas cidades, no papel que tiveram as suas sociedades urbanas e as culturas que criaram, onde urge procurá-las, dado que o mundo rural foi o que se manteve mais estável, e as cidades foram as que desencadearam as mudanças, partindo tanto dos impactos externos que receberam quanto das ideologias que elaboraram com elementos próprios e estranhos. (Romero, 2014, p. 27). 


\section{CONCLUSÕES FINAIS}

Lima aparece nesses textos como uma cidade-latino-americana, construída não apenas materialmente por meio de ações concretas de seus arquitetos, urbanistas, dirigentes e moradores, antigos e novos, mas também simbolicamente construída pelos discursos que a atravessam e engendram novas imagens. Ao lermos as narrativas dos literatos juntamente aos artigos dos arquitetos veiculados na $E A P$, percebemos como esses últimos demoram a perceber como a modernização da cidade dependia desses sujeitos que brotavam nas bordas da cidade. Vistas inicialmente como "pragas" que precisavam ser impedidas de crescer, logo entretanto as barriadas passariam a ser vistas como parte de uma cultura própria, que podia ensinar aos arquitetos de todo o mundo que a rigidez do modernismo já não era mis possível de ser levada adiante.

Pode-se aqui afirmar que a despeito de haver um interesse renovado pelas conexões possíveis entre literatura e história, os rendimentos dessa ligação continuam sendo em grande medida um desafio. Esse artigo tomou a cidade de Lima entre as décadas de 1940 e 1970 para um exercício de análise que relaciona as múltiplas dimensões que definem as cidades, com ênfase na dimensão das representações, em busca de contribuir para a história cultural urbana na América Latina. Buscou, portanto, pensar de que modo cidade e literatura se iluminam mutuamente.

O período enfocado é justamente o momento em que a cidade que se moderniza, vivendo os efeitos do segundo pós-Guerra. Como outras cidades do sub-continente, Lima viveu naquele período a intensificação do processo de urbanização com consequências que marcam até hoje sua paisagem. O surgimento das barriadas, ocupações precárias ao redor do casco histórico, contrastava com o investimento na edificação de unidades vecinales, grandes conjuntos habitacionais que sintetizaram os esforços da modernização urbana e arquitetônica do país. Ambas as experiências marcam os discursos dos arquitetos, que discutem a cidade e o que se quer dela nas páginas da revista El arquitecto peruano, dirigida por Belaúnde Terry, ao mesmo tempo que perpassam obliquamente as narrativas ficcionais, como se nota por exemplo na literatura de Julio Ramón Rybeiro, escritor contemporâneo que toma Lima como fulcro da sua experiência literária, entre outros.

É pensando nessa complexa circulação de ideias e imagens que fazem Lima existir como construção mental tanto quanto física que se explorou tais discursos, para compreender como as cidades se constituem também pelas diversas e variadas formas de representação que transmitem os significados imateriais e materiais daqueles artefatos.

\section{REFERÊNCIAS}

Anheim, É., Lilti, A. (2010). Savoirs de la littérature: introduction. Annales: Histoire, Sciences Sociales, Paris, Editions de l'E.H.E.S.S., 65eme année, v. 2, p. 253-260, 2010. https://doi.org/10.1017/S0395264900038518

Bradbury, M., Mcfairlane, J. (1989). Guia Geral do Modernismo. São Paulo: Cia das Letras, 1989.

Bresciani, M.S. (2018). Literatura e cidade. In: projetos. São Paulo: Alameda, 2018, p. 297-330.

Da cidade e do urbano: experiências, sensibilidades,

Caldas Torres, P. (2016). Transferencia de la idea urbana de ciudad-jardín y apropiación del modelo construido de la Unidad Vecinal en Lima. Revista invi, 31(87), 87-113. https://doi.org/10.4067/S0718-83582016000200003

Candido, A. (2000). Literatura e Sociedade [1970]. São Paulo: T. A. Queiróz, 2000.

Castro, A., Aravecchia-Botas, N. (2015). Visões e representações da marginalidade no território: de Lima à metrópole latino-americana (1950-1970). In: Urquidi, Vivian Grace Fernández-Dávila et. all. (Orgs). Anais do Simpósio Internacional "Pensar e Repensar a América Latina". PROLAM/USP (Programa de Pós-Graduação Interunidades em Integração da América Latina). São Paulo: ECA/USP, pp.73-87. https://sites.usp.br/prolam/wpcontent/uploads/sites/35/2015/06/Simp\%C3\%B3sio-Internacional-Pensar-e-Repensar-a-Am\%C3\%A9rica-

Latina_ANAIS_revisado1.pdf 
Castro, A.C.V. (2017). Literatura, cidade e sociedade na América Latina: Angel Rama e A cidade das letras. In: Anais do XXIX Simpósio Nacional de História. Brasília, $2017 . \quad$ Disponível em: https://anpuh.org.br/index.php/documentos/anais/category-items/1-anais-simposios-anpuh/35-snh29

Castro, A.C.V., Lira, J.T.C., Silva, J.M.C. (2020). Narrar por experiências. In: Jacques, P. B.; Pereira, M. S.; Cerasoli, J. F. (orgs.). Nebulosas do pensamento urbanístico, 50-83. Modos de narrar. Tomo III. Salvador: Ed.UBA.

Codognoto, B. L. (2021). A cidade latino-americana em seus termos: um olhar historiográfico à bibliografia produzida entre as décadas de 1950 e 1970. Relatório Parcial de Pesquisa de Iniciação Científica. FAUUSP/ Fapesp, São Paulo.

Congrains Martín, E. (1954). Lima, hora cero, Lima: Estudios peruanos.

Coutinho, E. F. (2021). A presença do Brasil e da América hispânica nos Congressos da Associação Internacional de Literatura Comparada. Revista Brasileira de Literatura Comparada, 23, 5-16. https://doi.org/10.1590/2596$\underline{304 \times 20212342 \mathrm{efc}}$

Dioses, E. A. (2020). Sociabilidad y configuración urbana moderna de los campamentos en Perú: La Oroya y Talara (1940-1970). Revista colombiana de sociología, 43(1), 215-234. https://doi.org/10.15446/rcs.v43n1.75467

Gorelik, A. (2005). A produção da "cidade latino-americana". Tempo social, 17, 111-133. https://doi.org/10.1590/S0103-20702005000100005

Hossiasson, L. (2007). A discreta obsessão de Ribeyro”. In: Ribeyro, J.R., Só para fumantes, 283-295. São Paulo: CosacNaify.

Huapaya Espinoza, J. C. (2014). Fernando Belaunde Terry e o Ideário Moderno. Salvador: Ed. UFBA.

Iegelski, F. (2021). História conceitual do realismo mágico - a busca pela modernidade e pelo tempo presente na América Latina. Almanack, 27. https://doi.org/10.1590/2236-463327ep00121

Kahatt, S. (2015). Utopias construídas: las unidades vecinales de Lima. Lima: Fondo Editorial PUCP.

Kahatt, S. (2020). Construcción y ausencia. Historia, teoría y crítica de la arquitectura peruana en el siglo XX. Arquitextos, (30), 129-137.

Leite, B. R. B., 2021. Avant-garde in Latin America: Manuel Bandeira in the universal localism. Translated from Portuguese by Fernanda Ranieri Silva. V!RUS, 22, July. [online] Available at: http://www.nomads.usp.br/virus/virus22/?sec=4\&item=6\&lang=en

López Maguiña, S. (2017). Cuadros del imaginario colonial en Lima la horrible de Sebastián Salazar Bondy. Letras (Lima), 88(128), 162-176. https://doi.org/10.30920/letras.88.128.8

Matos-Mar, J. (1977). Las barriadas de Lima 1957. Lima: Instituto de Estúdios Peruanos.

Meneses, U.B. (1996). Morfologia das cidades brasileiras: introdução ao estudo histórico da iconografia urbana. Revista USP, 30, 145-55. https://doi.org/10.11606/issn.2316-9036.v0i30p142-155

Rama, A. (2001). Meio século de narrativa latino-americana (1922-1972). In: Aguiar, F. e Guardini, S. (orgs.). Angel Rama: literatura e cultura na América Latina, 111-208. São Paulo: Edusp.

Ribeyro, J.R. (2007). Só para fumantes, São Paulo: CosacNaify.

Romero, J.L. (2002). América Latina. As cidades e as ideias (1976), Rio de Janeiro: Ed. UFRJ.

Díaz-Márquez, Á. M. (2019). Revisión bibliográfica sobre la circulación de ideas urbanas en América Latina y el Caribe. EURE (Santiago), 45(134), 279-294. https://doi.org/10.4067/S0250-71612019000100279

Rubio, D.R. (2015). Narrativa de la víctima: Fantasía y deseo en "Lima, hora cero". Lima: Pakarina Ediciones.

Santos, K.S. (2017). Habitação e cidade nos periódicos especializados latino-americanos: uma investigação a partir da revista El Arquitecto Peruano (1937-1977). Relatório Final de Pesquisa de Iniciação Científica. FAU USP/ Fapesp, São Paulo.

Terrones, F. (2006). "Lima la horrible" de Sebastian Salazar Bondy: destrucción y construcción de la ciudad. Disponível em: https://halshs.archives-ouvertes.fr/halshs-00167333/document. Acesso em 13/06/2021.

Turner, J.C. (1963). Dwelling resources in South America. Ekistics, 16 (97), 361-374.

Vega Centeno, P. (2017). La desigualdad invisible: el uso cotidiano de los espacios públicos en la Lima del siglo XXI. Territorios, (36), 23-46. https://doi.org/10.12804/revistas.urosario.edu.co/territorios/a.5097

Weisslitz, J. (1971). Migration rurale et intégration urbaine au Pérou. Espaces et Société, 3, 45-71.

Zapata, A. El joven Belaunde: historia de la revista El Arquitecto Peruano. Lima: Minerva, 1995. 
DECLARATION OF CONTRIBUTIONS TO THE ARTICLE - CRediT

\begin{tabular}{|c|c|}
\hline ROLE & ACastro \\
\hline $\begin{array}{l}\text { Conceptualization - Ideas; formulation or evolution of overarching } \\
\text { research goals and aims. }\end{array}$ & $X$ \\
\hline $\begin{array}{l}\text { Data curation - Management activities to annotate (produce } \\
\text { metadata), scrub data and maintain research data (including } \\
\text { software code, where it is necessary for interpreting the data itself) } \\
\text { for initial use and later re-use. }\end{array}$ & - \\
\hline $\begin{array}{l}\text { Formal analysis - Application of statistical, mathematical, } \\
\text { computational, or other formal techniques to analyze or synthesize } \\
\text { study data. }\end{array}$ & $\mathrm{X}$ \\
\hline $\begin{array}{l}\text { Funding acquisition - Acquisition of the financial support for the } \\
\text { project leading to this publication. }\end{array}$ & - \\
\hline $\begin{array}{l}\text { Investigation - Conducting a research and investigation process, } \\
\text { specifically performing the experiments, or data/evidence } \\
\text { collection. }\end{array}$ & $\mathrm{X}$ \\
\hline $\begin{array}{l}\text { Methodology - Development or design of methodology; creation of } \\
\text { models. }\end{array}$ & $X$ \\
\hline $\begin{array}{l}\text { Project administration - Management and coordination } \\
\text { responsibility for the research activity planning and execution. }\end{array}$ & $X$ \\
\hline $\begin{array}{l}\text { Resources - Provision of study materials, reagents, materials, } \\
\text { patients, laboratory samples, animals, instrumentation, computing } \\
\text { resources, or other analysis tools. }\end{array}$ & - \\
\hline $\begin{array}{l}\text { Software - Programming, software development; designing } \\
\text { computer programs; implementation of the computer code and } \\
\text { supporting algorithms; testing of existing code components. }\end{array}$ & - \\
\hline $\begin{array}{l}\text { Supervision-Oversight and leadership responsibility for the } \\
\text { research activity planning and execution, including mentorship } \\
\text { external to the core team. }\end{array}$ & - \\
\hline $\begin{array}{l}\text { Validation - Verification, whether as a part of the activity or } \\
\text { separate, of the overall replication/reproducibility of } \\
\text { results/experiments and other research outputs. }\end{array}$ & - \\
\hline $\begin{array}{l}\text { Visualization - Preparation, creation and/or presentation of the } \\
\text { published work, specifically visualization/data presentation. }\end{array}$ & $\mathrm{X}$ \\
\hline $\begin{array}{l}\text { Writing - original draft - Preparation, creation and/or presentation } \\
\text { of the published work, specifically writing the initial draft } \\
\text { (including substantive translation). }\end{array}$ & $X$ \\
\hline $\begin{array}{l}\text { Writing - review \& editing - Preparation, creation and/or } \\
\text { presentation of the published work by those from the original } \\
\text { research group, specifically critical review, commentary or revision } \\
\text { - including pre- or post-publication stages. }\end{array}$ & $X$ \\
\hline
\end{tabular}

